\title{
AS REDES SOCIAIS DO CRIME ORGANIZADO A perspectiva da nova sociologia econômica
}

\section{Edmílson Lopes Júnior}

\section{Introdução}

Este artigo aponta elementos para uma compreensão sociológica do crime organizado no Brasil atual. Duas perspectivas analíticas servem de referência para essa empreitada: a chamada "Nova Sociologia Econômica" (NSE) e a "análise de redes". Da primeira, tomo como referência algumas das discussões centrais a respeito de conceitos nodais, como transação econômica, contrato e confiança. Nesse percurso, referencio-me nas seminais elaborações do historiador econômico Avner Greiff. A nossa aposta é a de que conceitos e abordagens, inicialmente direcionadas para a apreensão das relações de mercado, podem e devem ser mobilizadas para uma apreensão mais rigorosa das múltiplas realidades sociais comumente definidas como ex-

Artigo recebido em outubro/ 2007

Aprovado em maio/2008 pressões do crime organizado. Já em relação à análise de redes, recorro a situações concretas, abordadas em pesquisas desenvolvidas ou em desenvolvimento, para apontar uma trilha a ser seguida na investigação sociológica de redes sociais criminosas.

A NSE já ultrapassou aquela fase na qual poderia ser identificada, seguindo-se os critérios de Jeffrey Alexander, como a expressão de um "novo movimento teórico" (Alexander, 1987). Vinte anos após a publicação de "Economic action and social structure: the problem of embeddedness", o seminal artigo de Mark Granovetter que inspirou não apenas uma redescoberta do potencial sociológico da obra de Karl Polanyi, mas deu um novo fôlego à sociologia econômica (não por acaso, a partir de então, identificada como "nova"), esse subcampo, pleno de potencialidades teóricas e possibilidades de pesquisa, já não pode contar mais com a benevolência concedida aos adolescentes. No alvorecer de 
sua maturidade, esse "movimento" necessita remodelar a sua agenda e apontar suas baterias analíticas para a produção de narrativas sociológicas que dêem conta de alguns dos elementos centrais do capitalismo como sistema econômico. Trilha que pode levar a produção de importantes "teorias de médio alcance" e que deve ser complementada por investigações mais robustas, que ambicionem apreender os fios que ligam as diversas partes desse sistema. Essa é a aposta de Richard Swedberg em suas publicações mais recentes. Fazemo-la nossa também ao adentrarmos o território de areia movediça que constitui o universo social que conecta crime e economia, com o desiderato de produzir uma análise que, incorporando aportes e pistas analíticas da sociologia e da economia, possibilite uma compreensão mais nuançada das redes sociais ligadas (direta ou indiretamente) ao crime organizado no Brasil contemporâneo.

Mais do que no alargamento de um campo teórico, a abordagem aqui proposta encontra justificativa no fato de que um aclaramento da complexidade do crime organizado é uma tarefa que pode contribuir, mesmo que indiretamente, para um dimensionamento dos esforços e recursos empregados no seu combate. Se há um acordo, mais ou menos generalizado, de que aquela modalidade de organização delinqüente é um daqueles "outros" (a tríade se completa com a corrupção e o terrorismo) que, sendo decifrados ou não, podem devorar a democracia, então o conhecimento sobre o terreno social no qual essa erva daninha se reproduz só pode ser concebido como estratégico. E na produção desse conhecimento, postulo, o "econômico" da NSE não é mero complemento. Isso porque categorias e conceitos enraizados no universo disciplinar da economia, revisados, ampliados e redefinidos na produção sociológica da vida econômica dos últimos anos, são referências incontornáveis. Por isso mesmo, neste trabalho, recorro, não poucas vezes, a termos como risco, confiança e monopólio, dentre outros tão semanticamente carregados e, amiúde, usados em narrativas sobre as transações econômicas "regulares" para dar sentido às relações e às estruturas sociais erigidas no extenso e complexo universo social identificado como "crime organizado".

O alargamento da agenda da NSE é, assim, um ponto de partida para a realização de um obje- tivo mais terreno: produzir uma apreensão cognitiva do crime organizado, buscando dar conta tanto da natureza mesma de suas transações quanto do terreno social que o alimenta e sobre o qual se desenvolve. A base empírica sobre a qual se assenta esta narrativa sociológica é fornecida pelos relatórios de operações desenvolvidas pela Polícia Federal nos últimos três anos, pelo trabalho desenvolvido por duas Comissões Parlamentares de Inquérito (CPIs) da Câmara dos Deputados e outra da Assembléia Legislativa do Estado de São Paulo.

Nesta empreitada analítica, guio-me pela hipótese de que a melhor apreensão do crime organizado é aquela que o tome como um processo situado em um continum que vai da atividade legal até o evento delituoso. Essa perspectiva implica a rejeição de uma retórica, bastante mobilizada nos repertórios da mídia contemporânea, nas conversas do dia-a-dia e nas intervenções de governos e organismos internacionais, que cristaliza o crime organizado como um monstro monolítico, como se ele fosse sempre a expressão do oposto daquilo que se realiza nas transações sociais cotidianas. Obviamente, seguir essa senda analítica não significa negar a existência de referentes que autorizem a construção de narrativas focadas no grotesco e no demasiado estranho. Mas, e aí insinuo um pouco da tese que busco defender aqui, quanto mais nos aproximamos dos eventos sociais tidos como representativos do crime organizado, mais nos damos conta da sua banalidade. Uma banalidade da qual, não raro, os próprios atores procuram fugir construindo representações grandiosas de si mesmos e de seu universo. Um exemplo: tanto o "narcorrido" como o "proibidão", gêneros musicais alimentados pelo narcotráfico, no México e no Brasil, nutrem-se da necessidade de construir uma boa apresentação de si dos traficantes, a qual, não raro, corresponde às expectativas presentes no imaginário social local a respeito do bandido destemido.

Para operacionalizar a investida analítica proposta, sirvo-me de sugestões formuladas por Granovetter (2005), especialmente da sua idéia provocadora de que a investigação sociológica de fenômenos como corrupção, crime organizado e terrorismo, entre outros, deve levar em conta a apreensão das redes sociais que os estruturam. A análise de redes 
permite, no nosso caso, contornar as "evidências do mundo", tomando por problema aquilo que comumente é tido como um "dado" e ponto de partida para a análise. Pensemos, por exemplo, nas conseqüências da não-problematização do que seja um "grupo criminoso". Os ganhos potencializados pela análise de redes não são poucos, na abordagem desse universo. Um primeiro impacto positivo é que contribui para realçar o fato de que as redes pessoais que fornecem as bases para as atividades criminosas são distintas no que dizem respeito à natureza de suas atividades (um esquema de fraude da previdência nutre-se de relações muito distintas daquelas mobilizadas no tráfico de drogas, por exemplo). Em segundo, o lugar da confiança e da natureza dos laços (fortes ou superficiais) diz respeito não apenas à atividade criminosa, mas ao universo social de origem dos agentes. Em terceiro, quando se trabalha com a noção de "grupo" (isso não significa, obviamente, que eles não existam nas atividades criminosas), perde-se a dimensão do grau variado de comprometimento (e do papel desempenhado) de cada um dos indivíduos na produção do evento criminoso.

Antes de prosseguir, devo apresentar, mesmo que sumariamente, duas definições de termos que são centrais neste artigo: crime organizado e rede social do crime. Existem inúmeros trabalhos dedicados a fazer o levantamento das definições mais usuais de crime organizado. Os organismos internacionais, comumente, definem o crime organizado como sendo aquele tipo de atividade criminosa desenvolvida por mais de duas pessoas e encimada pelo objetivo de conseguir dinheiro e poder. Estudiosos do crime, como Jay Albanese, também se debatem com o desafio de construir definições objetivas e amplamente aceitáveis de crime organizado (Albanese, 2000). Entretanto, e assumindo aqui uma posição que é em parte tributária da perspectiva relacional e anticategorial expressa por Emirbayer (1997), trabalho com uma definição mais provisória e menos fixa de crime organizado. Proponho, seguindo de perto Beare (1997), defini-lo como um processo, não como expressão de uma atividade ou de um tipo específico de ator. Isto implica, em primeiro lugar, o reconhecimento de que a própria definição do que seja crime organizado está envolta em um in- tricado embate político e ideológico. E, em segundo, que tal definição é também performativa. Isto é, ajuda a construir (dar visibilidade social) ao fenômeno que procura identificar.

No que diz respeito à rede social do crime, seguindo aqui a sugestão do criminologista alemão Klaus von Lampe (2003), defino-a como um conjunto de atores que, conectados uns aos outros de alguma forma, dão suporte, em alguma medida, a uma atividade ilegal (cuja durabilidade e extensão espacial variam consideravelmente). Tais redes, entendo, devem ser tomadas como referências empíricas da análise sociológica do crime organizado. E, assim como nas redes sociais da "superfície", nas empresas, para citar um exemplo, essas redes criminosas também dependem, fortemente, de "animadores" detentores de "habilidades sociais" para lidar com informações limitadas sobre os cenários nos quais atuam.

O que segue é, ainda, uma visão bastante panorâmica a respeito do crime organizado. Para tornar mais apresentável o trabalho, organizei os diversos tópicos de minha abordagem em duas partes.

\section{Transação econômica, instituições e crime organizado}

\section{Economia informal e economia ilegal}

Uma narrativa razoavelmente influente, alicerçada em uma apreensão fenomênica da economia informal nas grandes cidades latino-americanas, tem apontado o mosaico de bazares de nossos centros urbanos como uma conseqüência dos ajustes econômicos incluídos nas reformas econômicas das duas últimas décadas do século XX. Com ampla audiência no público situado no espectro político mais à esquerda, essa narrativa, presente, por exemplo, nos ensaios de Francisco Oliveira (2003) e de Mike Davis (2006), embora um tanto escatológica e em que pese o raquitismo de sua explicação funcionalista (na qual o "neoliberalismo" emerge com o estatuto de um ator), toca em um ponto importante para a reflexão sobre as conexões entre o crime organizado e a vida econômica, especialmente no Brasil. Refiro-me menos à incapacidade de integração de amplas massas à economia formal e, mais, 
ao lugar cada vez mais central ocupado pela economia informal na vida social do país. Tais autores, embora demonstrem acuidade crítica para desconstruir narrativas como aquelas de De Soto (1987), que, ingenuamente (ou não tanto assim), creditam potencialidades criativas à informalidade econômica, não empreendem um exercício, o qual a bem da verdade cientistas sociais ligadas à Cepal, de algum modo, olham de frente na segunda metade do século XX: debruçar-se sobre a natureza e o papel das instituições na vida econômica do continente.

E é da inquirição sobre o caráter da economia informal e da sua fragilidade institucional que podemos tirar importantes lições para pensar o lugar do crime organizado na vida social e econômica brasileira neste início de século. Uma reflexão como essa, mesmo que dirigida genericamente a toda a América Latina, foi empreendida por Centeno e Portes (2003), a partir de uma perspectiva analítica fortemente influenciada pela NSE.

Não é nossa intenção, e foge completamente ao escopo do presente trabalho, uma maior discussão sobre a economia informal, mas se lhe faço referência é porque, à semelhança da economia ilegal (o estabelecimento de fronteiras entre uma e outra é sempre precário e dependente de arranjos políticos frágeis e provisórios), a economia informal se alicerça mais em uma confiança produzida por redes sociais do que por instituições que se alimentam e se nutrem da provisão de condições necessárias para a efetivação de contratos que independem da pessoalidade. Obviamente, não se trata de negar o "encrustamento" (embededdness) das atividades econômicas, mas, e aqui sigo de perto Centeno e Portes (Idem), de reconhecer que, se as redes de relacionamentos pessoais (e a confiança que elas alimentam) são importantes, nenhuma economia moderna sobrevive sem a sedimentação de instituições que dêem garantia aos contratos construídos na impessoalidade.

As redes sociais que nutrem a economia informal, em muitas situações alicerçadas no parentesco ou no lugar de origem, como no caso dos migrantes (Lopes Jr., 2002), não se constituem em uma alternativa razoável às salvaguardas institucionais para terrenos mais amplos da vida social. Isso não significa que tais redes não cumpram papel decisivo na manutenção da produção e oferta de bens e serviços essenciais à parte significativa da população brasileira. Basta levar em conta que tais redes são responsáveis pela provisão de serviços como transportes ("alternativos"), locação de imóveis, segurança pessoal e comunitária, TV a cabo, telefonia e "planejamento urbano" em muitas áreas urbanas brasileiras, além, obviamente, de bens de consumo os mais diversos.

E a evolução de algumas dessas áreas da vida social nos últimos anos no país aponta muito claramente para a estreita conexão entre economia informal e economia ilegal. Assim, não é raro que os agentes que fornecem segurança e organizam a distribuição das linhas de "transporte alternativo" nas grandes cidades sejam os mesmos que vendem segurança para atores importantes do crime organizado. Tais redes, não raro, pré-existem às atividades que agora dão suporte. No Rio de Janeiro, são grupos expressivos dessas redes, animadas por policiais e ex-policiais, que disputam com os membros do "movimento" (os grupos ligados ao narcotráfico) o controle de amplos territórios urbanos.

Se, no que diz respeito à vida econômica mais geral, a economia informal termina cumprindo um papel funcional, no que diz respeito ao crime organizado, os pontos de contato vão além da mobilização, em muitas situações, das mesmas redes sociais como suporte. Não poucas atividades da economia informal têm, seja na produção ou na distribuição, similaridades com a economia ilegal. Profundamente enraizada no mundo social, a pirataria de música, filmes e programas para computadores, atividade tratada como uma "epidemia", não por poucos, é um bom exemplo dessa situação.

O inevitável conflito entre os atores da economia informal e o Estado é agudizado em situações nas quais setores ou territórios da vida social são subtraídos do exercício do monopólio da violência legítima. $\mathrm{O}$ recurso à violência, amenizado pela inclusão da corrupção, torna-se mais acentuado, dado que, geralmente, esse é o instrumento que se tem à mão para o enfrentamento dos rompimentos unilaterais do contrato.

A confiança que emerge de tais laços é, por outro lado, frágil para a construção de bases seguras para a emergência de instituições que forneçam suportes a investimentos de médio e longo prazo. 
Daí que os lucros auferidos tanto na economia informal quanto na ilegal direcionem-se prioritariamente aos investimentos especulativos mais seguros (ouro e dólar) e ao consumo suntuoso (automóveis e mansões, além de atividades festivas destinadas à conquista de algum reconhecimento social). No caso das redes sociais mais enraizadas no crime organizado, a experiência na lavagem de dinheiro ilícito contorna essa situação, com investimentos no setor imobiliário (as operações da PF apontam para a importância crescente do litoral do nordeste do Brasil como alvo das investidas de criminosos europeus), no setor de transportes e distribuição de combustíveis (esse o campo de ação de grupos criminosos nacionais, como o PCC) e no setor de diversão (boates e casas de jogos), no qual o crime organizado conta com um acúmulo significativo de experiências.

A Figura 1 condensa um pouco do que foi acima apresentado.

\section{Crime organizacional e crime organizado}

A análise desenvolvida por Baker e Faulkner (1993) sobre as redes ilegais envolvidas em uma conspiração ocorrida na segunda metade do século $\mathrm{XX}$ nos Estados Unidos, para manipular preços no mercado de equipamentos eletrônicos pesados, ajuda-nos a construir uma tipologia dos crimes que ligam organizações à vida econômica. Refiro-me à identificação feita pelos autores de determinadas práticas como sendo "crimes organizacionais", isto é, crimes desenvolvidos em organizações, geralmente legais (firmas, por exemplos), para estabelecer o monopólio sobre nichos ou áreas do "mercado". Essa demarcação é importante na medida em que, especialmente nos últimos anos, e mais precisamente como resultado de ações empreendidas por promotorias públicas, tem-se tornado comum a nominação de grupos ou organizações responsáveis pela defesa de interesses corporativos específicos (empresas de transportes públicos, cooperativas de serviços médicos, empreiteiras, prestadores de serviços ao Estado etc.), quando descobertas envolvidas em ações ilícitas para manipular preços, como "máfias". Não raro, então, somos bombardeados por informações a respeito de "máfia dos trans- portes", "máfia dos postos de gasolina", "máfia dos empreiteiros" etc. No geral, esses crimes, os quais, seguindo a indicação de Baker e Faulkner, nomeamos como "crimes organizacionais", são articulados e desenvolvidos a partir de redes sociais legais.

Se fronteiras porosas se interpõem entre as atividades econômicas "legais" e "ilegais", essa situação se traduz muito concretamente no agenciamento para ações nas sombras por indivíduos envolvidos em redes legais, pertencentes ao que se convenciona identificar como o "mundo da superfície" (upperworld). Em algumas das operações desencadeadas pela Polícia Federal de 2003 a 2005, o "crime organizado" revelado correspondia muito mais ao tipo apontado acima.

\section{Confiança, destino e "cultura do risco"}

A confiança ocupou sempre um lugar central na vida social. Na modernidade, porém, deslocada dos ambientes de interação face a face, ela se assenta cada vez mais em sistemas abstratos (medicina, bancos, engenharia etc.). Tais sistemas, denominados por Anthony Giddens como "sistemas peritos", condensam conhecimentos sobre zonas específicas da vida social. Dessa forma, a confiança, em sociedades tipificadas como "pós-tradicionais" por Giddens (1995), pressupõe sempre mecanismos de desencaixe da vida social dos seus entornos locais. Entenda-se por "desencaixe" uma perda de controle das pessoas sobre o espaço e o tempo locais.

Estreitamente articulada à noção de confiança, temos, na obra giddeniana, o conceito de risco. Nessa articulação, Giddens $(1993,2003)$ flerta com a noção de "sociedade de risco", formulada pelo sociólogo alemão Ulrich Beck. Tal como a confiança, o risco também teria sido guindado, no período moderno, a um lugar de destaque nas nossas relações sociais. A centralidade do risco é, para os dois autores, diretamente proporcional à marginalidade do destino. $\mathrm{Na}$ medida em que este último implicou sempre, em alguma medida, a pressuposição de um futuro pré-determinado, mas desconhecido e fechado à colonização do presente, a confiança, cada vez mais alicerçada em um conhecimento do mundo que se supõe racional, alimenta-se e nutre 
Figura 1

Tipos de Atividades Econômicas e seus Inter-relacionamentos

I. Definições

$+=$ Lícito - = llícito

\begin{tabular}{|c|c|c|}
\hline $\begin{array}{c}\text { Processos de produção e } \\
\text { distribuição }\end{array}$ & Produto final & Tipo econômico \\
\hline+ & + & Formal \\
\hline- & + & Informal \\
\hline- & - & Criminoso \\
\hline
\end{tabular}

\section{Relacionamentos}

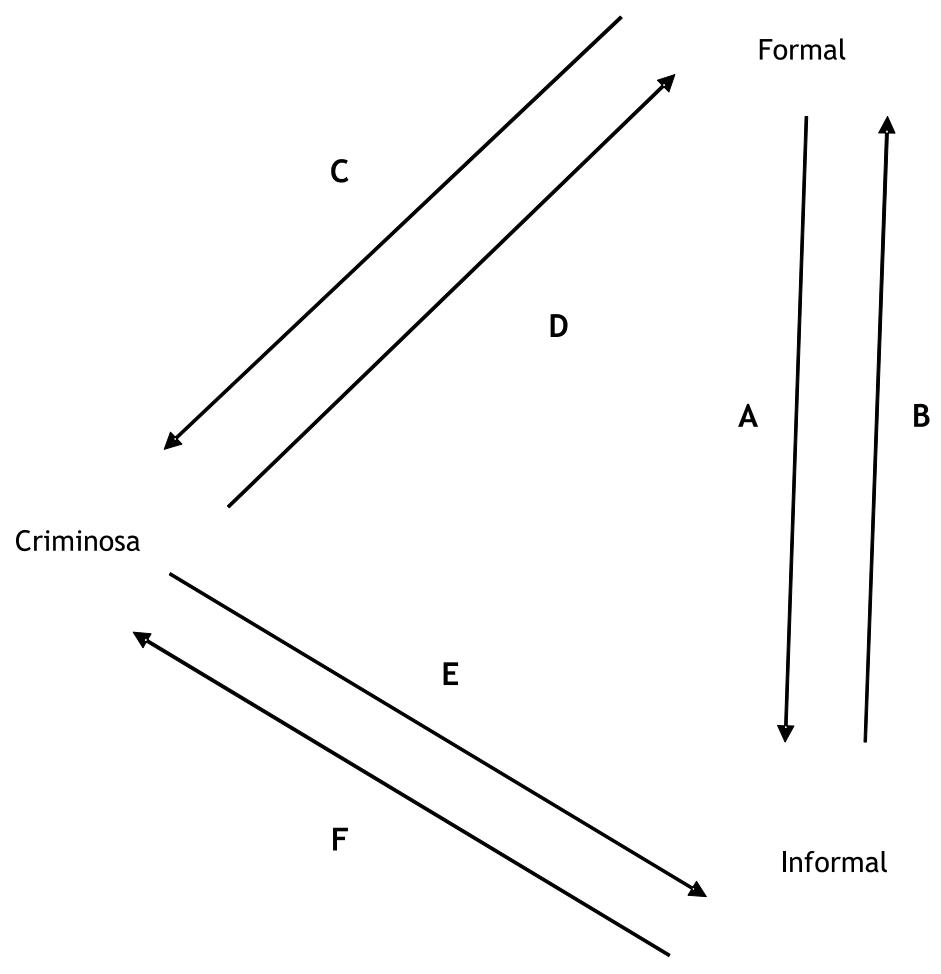

A. O Estado cumpre o papel de regulação, há competição de grandes empresas que são fontes de inovação e capital.

B. Predomina o consumo de bens industrializados baratos e uma força de trabalho flexível.

C. Interferência do Estado descontínua e demanda por certos bens controlados.

D. Corrupção envolve o aparelho de Estado.

E. Capital, demanda por bens, novas oportunidades de ganhos.

F. Produtos baratos, força de trabalho flexível. 
uma cultura do cálculo. E é o cálculo (base sobre a qual traçamos prospectivamente os cenários futuros) que nos conduz à colonização do futuro. $\mathrm{E}$, na medida em que, com base em cenários prospectados, fazemos escolhas, apostas e tomamos decisões coletivas ou individuais, confiança e risco tornam-se cada vez mais importantes em nossas vidas.

A elaboração giddeniana pode contribuir para que possamos construir uma apreensão mais complexa das transações econômicas efetuadas em ambientes de radical incerteza. Entretanto, e esse não é um mero detalhe, e quando essas transações de risco ocorrem em uma ambiente em que inexistem salvaguardas institucionais? Assim, se a discussão sobre confiança e risco é importante como subsídio para uma reflexão sobre o contexto social dentro do qual se desloca o crime organizado, necessitamos ir um pouco além se quisermos perscrutar melhor os cenários nos quais se desenrolam as negociações econômicas criminosas. Antes de avançarmos um pouco mais nessa direção, vale a pena realçar, mesmo que rapidamente, a importância da "cultura do risco" na vida econômica moderna.

Decerto, essa "cultura do risco" é um dos vetores instituidores de inúmeros mercados singulares. Pensemos, por exemplo, no mercado de seguros, analisado exemplarmente em um dos trabalhos tidos como inaugurais da Nova Sociologia Econômica (Zelizer, 1979): sem a legitimação sociocultural da vida como um "projeto", ele seria impensável. Na prática, temos a incorporação, na vida diária de um número cada vez maior de pessoas, do cálculo dos cenários futuros de sua própria existência. O risco, agora "manufaturado" (não mais resultado apenas das forças incontroláveis e desconhecidas da natureza), isto é, socialmente percebido como um produto de interações e acontecimentos que podem ser avaliados e, em certa medida, monitorados e mitigados, espirala a calculabilidade para as dimensões mais recônditas do indivíduo moderno.

Assim, tal como as torrentes sócio-psíquicas liberadas pela modernização do capital, que destronam a tradição em uma espiral crescente (como a leitura do jovem Karl Marx, em vertiginoso manifesto, nos ensinou), também a cultura do risco não deixa intocado (isso não signifique que subordine completamente) nenhum espaço da vida social. E, mesmo sem adquirir o pacote inteiro das leituras neo-marxistas sobre o crime organizado, pode-se levar a sério a afirmação de que as mesmas forças e os valores que estão em jogo na economia capitalista em geral também o estão na economia das sombras patrocinada pelo e alimentadora do crime organizado.

$\mathrm{Na}$ sociedade brasileira, a "cultura do risco" assume contornos próprios. A apreensão destes pode contribuir para uma melhor apreensão dos contextos nos quais vegetam as redes sociais do crime organizado.

Um dos primeiros elementos que singularizam a "cultura do risco" na sociedade brasileira é a disseminação, no universo social das classes populares, do fenômeno que o sociólogo Jessé Sousa, em leitura inspirada na obra de Pierre Bourdieu, denominou de "habitus precário" (Sousa, 2003), o qual se traduz, na vida cotidiana de milhões de pessoas, na in-corporação (o hífen aqui não é gratuito) da desigualdade social como algo "natural" e na insegurança de seu lugar no mundo (alimentada pela ausência de espaços e situações positivas de reconhecimento social ${ }^{2}$ ), algo que se traduz na percepção do próprio corpo como uma duvidosa fortaleza ${ }^{3}$. Não por acaso esse é o alvo das incursões costumeiras do poder (tanto do pátrio poder, na família, que, mesmo em crise de legitimação social da sua forma patriarcal, ou exatamente por causa desta, é cada vez mais o lócus do disciplinamento por meio dos maus-tratos e da tortura; quanto das forças repressivas do Estado, no âmbito social mais geral).

Esse traço fornece lastro para um forte presenteísmo na nossa vida social. Com isso, a "cultura do risco", esse vetor cultural da vida econômica e social do mundo globalizado, não é eliminada, mas radicalizada no Brasil. O corolário disso é uma grande dificuldade de consolidar instituições que incorporem o planejamento a médio e longo prazo. Em certo sentido, a própria análise do risco (por exemplo, das implicações mais profundas das ações desenvolvidas hoje) é subordinada a uma avaliação dos prazeres e ganhos mais imediatos.

Um segundo elemento a ser ressaltado sobre a cultura do risco no Brasil diz respeito a um traço que, analisado exemplarmente por Florestan Fernandes em uma das obras seminais da sociologia 
brasileira, pode ser identificado como ausência dos requisitos sócio-psíquicos para a navegação social na ordem competitiva. A vigorosa análise de Fernandes (1978) sobre a "inadaptação" do negro à ordem capitalista do final do século XIX e das primeiras décadas do século XX pode ser mobilizada, hoje, para a apreensão dos cenários que servem de pano de fundo para o desenvolvimento das atividades das redes sociais relacionadas com o crime organizado. Assim, e invertendo a argumentação desenvolvida por Fernandes, talvez pudéssemos propor que essa "ausência de requisitos" se apresenta, hoje, muito menos como "inadequação" e mais como o contrabando de elementos típicos da ordem tradicional para as relações de mercado. O que, certamente, nos leva ao problema do encrustamento (embeddedness), nos termos propostos por Granovetter (1985).

Indo além dos termos e dos problemas de Fernandes, uma abordagem ancorada na NSE pode nos levar a pensar a "ordem competitiva" de forma menos abstrata. Assim, esta é percebida como muito mais matizada quando, por exemplo, incorporamos a noção de "múltiplos mercados", 4 com distintas formas e lógicas de legitimação social. Em conseqüência, podemos dar um melhor contorno ao problema da "inadequação". Quando nos defrontamos com os dados de realidade, o fenômeno é, hoje, menos de inadequação e, muito mais, de re-encaixamento (reembeddedness). Basta que tomemos como referência à recorrência a práticas criminosas por agentes econômicos atuante na superfície (muito além daquelas mais ou menos legitimadas nas disputas de mercado, como a espionagem industrial e a sabotagem de produtos dos competidores), dentre as quais a eliminação física de concorrentes ou de agentes da regulação estatal (fiscais do trabalho, do meio ambiente e da saúde, entre outros).

\section{Transações, instituições e o enfrentamento da incerteza}

Se as colocações precedentes a respeito de confiança e risco nos ajudam a pensar sobre transações econômicas em situações de incerteza, aclaram muito pouco sobre os contextos institucionais construídos para tornar factível as transações em tais situações. Assim, talvez alarguemos os nossos ganhos heurísticos se levarmos em conta, na construção de uma abordagem sociológica sobre o crime organizado, a ousada e criativa investigação sobre a emergência de instituições "necessárias" às transações econômicas na Baixa Idade Média empreendida pelo historiador econômico Aner Greif. Sem descurar de uma apurada investigação histórica nem se desviar para uma leitura pobremente funcionalista (que a palavra "necessária", escrita mais acima pareceria anunciar), Greif $(1993,2004)$ mobiliza a teoria dos jogos para construir um modelo razoavelmente convincente a respeito do desenvolvimento institucional distinto no Magreb e nas cidades comerciais italianas. A questão que Greif toma como ponto de partida é: como é possível o cumprimento dos contratos na vida econômica em um contexto no qual as separações espaciais fornecem poucas garantias aos agentes? Obviamente, para o "raciocínio sociológico" dominante (mesmo na NSE), essa é uma questão tão curtida nos barris do institucionalismo econômico que é difícil de ser facilmente assimilada.

Trata-se, no caso, de uma objeção compreensível. Para o sociólogo durkheimiano ou para o antropólogo douglasiano, ${ }^{5}$ essa questão, além de "ingênua", demonstra ignorância a respeito de clássica abordagem sobre as dimensões não contratuais do contrato. Entretanto, contando com o "princípio de generosidade" do leitor, sigamos adiante com o próprio Greif:

Dado que as relações de troca trazem atrelada uma se-
paração temporal e/ou geográfica entre o quid e o quo
intercambiados, essas relações precisam de um meca-
nismo que garanta o cumprimento das obrigações con-
traídas, sejam estas explícitas ou implícitas. Dá-se por-
que se espera receber. Sem esta expectativa, os indiví-
duos não realizariam trocas. Portanto, as trocas exigem
mecanismos que possibilitem aos indivíduos se compro-
meterem com o fiel cumprimento dos termos contratuais.
Tais mecanismos aliviam o problema fundamental das
trocas, porque facilitam que as partes contratantes sai-
bam ex ante que é do próprio interesse delas cumprir ex
post com as obrigações estabelecidas no contrato (Greif,
2004 , p. 10).

Greif constrói um modelo que, em parte, aproxima-se bastante daquele tipo de exercício geralmente empreendido por antropólogos nos anos 1950 e 1960: focaliza sobre os elementos endógenos da evolução institucional de determinada sociedade. Embora tenha, no horizonte, um conceito reificado 
como o de "custo de transação", Greif produzirá uma instigante análise da evolução das transações que requeriam um agente (executor da ação e alvo da confiança) e um principal (aquele que confia e, na investigação empreendida por Greif, se arrisca a transferir bens ou valores em troca de algo ${ }^{6}$ nos século XII e XIII. As suas referências para análise são: a) os judeus que, emigrados de Bagdad no século XII, estabeleceram-se no Magreb; e b) os comerciantes das principais cidades italianas do período. Apoiando-se em dados que comprovariam que o agenciamento nesses dois universos diferia devido ao fato de que a agência se realizava mais completamente entre os segundos que os primeiros (dado que, no Magreb, os agentes eram também co-responsáveis ou parceiros das transações efetuadas), Greif propõe a seguinte interpretação: o maior distanciamento social entre agentes e principais (forte no caso das cidades italianas) era compensado por instituições que compensavam a fragilidade dos laços de solidariedade.

Assim, enquanto nas cidades italianas os agentes, desprovidos de capital, recebiam encomendas para dar seguimento a determinadas transações, e, por isso mesmo, eram "assalariados", os comerciantes judeus do Magreb, apoiados em fortes redes de confiança pessoal, não foram constrangidos a construir instituições de salvaguarda para os seus negócios. Nas cidades italianas, a confiança (ou a ausência de) criava uma situação de muita incerteza, e Greif apresentará muitas evidências históricas do lento processo de construção de salvaguardas paras evitar o oportunismo dos agentes (o não-cumprimento de suas tarefas de encomenda). Essas salvaguardas, diga-se de passagem, também se faziam necessárias em face dos obstáculos colocados pelo controle feudal das atividades comerciais. Assim, lidando com laços fracos e incerteza, os comerciantes das cidades italianas foram cimentando o terreno para instituições que regulassem as transações entre indivíduos que não pertenciam a mesma comunidade e nem partilhavam os mesmos valores. A história das organizações econômicas e políticas dos últimos séculos, de certo modo, expressa o impacto das instituições surgidas em resposta aos laços fracos.

A abordagem acima nos aponta preciosos elementos para a investigação sociológica sobre as re- des sociais ligadas ao crime organizado no Brasil. Fincadas em um chão social adubado pelo paternalismo, patrimonialismo e clientelismo, algumas das redes sociais reveladas pelas operações desencadeadas pela Polícia Federal são fortemente enraizadas na vida social. Reproduzindo modelos de clientela, expressam, como nos casos das redes de predação dos recursos públicos (seja por meio de fraudes contra a previdência ou nas diversas formas de apropriação de bens do Estado), um modelo de relacionamento dominante que é o da patronagem. Situam-se aí mais da metade das redes reveladas pelas operações realizadas pela PF de 2003 a 2005. Tais redes reproduzem modelos verticais de relacionamento e, assim sendo, produzem menos cooperação e solidariedade e mais cumplicidade submissa e medo. Isso não significa - longe disso! - que se cristalizem em estruturas organizacionais verticais, como nas "máfias imaginadas". Essa é uma verticalização que, em certo sentido, já se encontra fortemente enraizada no universo social e é apenas exacerbada nesse universo das práticas delituosas.

Temos, então, uma situação bastante distinta daquela analisada exemplarmente por Greif: laços fracos, já que expressão de ligações verticais, e ausência de qualquer possibilidade de salvaguardas institucionais mais amplas para as transações a serem efetuadas. Isso é bem mais evidente no universo do mercado de drogas e armas. Nesses mercados, a incerteza é contrabalanceada pela construção da reputação dos principais. Daí o recurso à violência extremada, como a tortura e a eliminação física de desafetos, ter se tornado de uso corrente. Todos sabem com quem, e de quem, se está falando.

\section{As redes sociais do crime organizado}

\section{Ordem competitiva e redes sociais criminosas}

Se o intercâmbio de bens produzidos ilicitamente (originários da pirataria ou de um processo produtivo realizado à margem da regulação) é um traço comum à economia formal e à economia ilícita, apenas nesta última existe uma multiplicidade de "mercados específicos" cujos bens são ilegais em todo o ciclo - da produção ao consumo, como 
o de drogas. E é também essa economia que é dinamizada por redes sociais abertamente criminosas.

Não raro, a mobilização de instrumentos ilegais por determinado conjunto de atores que atuam em mercados legais e fortemente competitivos tem incentivado uma extensa produção midiática sobre a existência de "máfias" em determinados "nichos". Nesses casos, mais do que crimes organizacionais, estamos lidando com aquela "super-adequação" que mencionei mais acima. Os atores aqui revelados, como os jovens delinqüentes que roubam para adquirir bens posicionais na análise clássica de Robert Merton, também não são sub-socializados. Muito pelo contrário, querem os ingressos para o sucesso na ordem social dominante. Eles incorporaram tão fortemente o ethos da lógica competitiva que mobilizam instrumentos de outras ordens, ilegítimos ou ilegais, para a consecução dos seus objetivos.

Não é surpreendente, portanto, que, na análise dos resultados alcançados pelas operações desenvolvidas pela Polícia Federal, de 2003 a 2005, sobressaiam fraudes em nichos competitivos do mercado (especialmente nos setores que vendem serviços públicos ou supervisionados pelo Estado). Igualmente significativas são as ações criminosas relacionadas a fraudes em setores do mercado varejista, como o de combustível. Neste, operações da Polícia Federal, como aquela denominada "Poeira no Asfalto", revelam esquemas, envolvendo proprietários de postos de combustíveis, policiais e agentes de fiscalização, para adulterar a composição do produto final (álcool ou gasolina) vendido aos clientes.

A Figura 2, formulada por von Lampe (2005), ajuda-nos a situar melhor essa problemática. Adaptando-a à realidade das redes sociais ligadas ao crime organizado revelados pelas operações desenvolvidas pela Polícia Federal nos últimos anos, poderíamos apontar que o "contexto institucional", com as suas redefinições de controle e de legitimidade, tem um importante peso como variável explicativa de uma vasta gama de crimes.

Por outro lado, se não se pode apreender o crime organizado sem se levar em conta o contexto institucional, não se pode igualmente subestimar o peso de necessidades estreitamente vinculadas às novas formas de sociabilidades (como, por exemplo, a demanda por cocaína e drogas sintéti- cas das classes médias urbanas) ou práticas culturais socialmente enraizadas (jogos de azar e prostituição). As redes sociais que alimentam essas necessidades têm contornos próprios e, não raro, implicam um grau elevado de cumplicidade e troca de confiança entre clientes e fornecedores (usuários de drogas e apostadores).

\section{As redes sociais do crime organizado: dois casos}

Arriscando uma aproximação maior com o universo e a natureza das redes sociais relacionadas ao crime organizado, aponto, a seguir, dois exemplos ilustrativos. O primeiro deles toma como referência uma pesquisa já concluída. ${ }^{7}$ Em um segundo momento, abordo as redes de pilhagem do Estado desveladas nas operações realizadas pela Polícia Federal nos últimos anos e pelo trabalho de diversas Comissões Parlamentares de Inquérito (CPIs) tanto da Câmara Federal quanto de algumas assembléias legislativas de estados como São Paulo e Rio Grande do Sul.

\section{a) Presídios e redes sociais}

Mais fronteiras porosas do que muros separam o mundo oficial daquele das ações criminosas. Se existem "evidências" que corroboram as imagens de um mundo do crime alicerçado em redes sociais de confiança rigidamente hierarquizadas (reproduzindo o padrão mafioso "chefe-soldado") e construído sob a égide de normas e regras muito próprias, trata-se de não tomar tais dados impressionistas da realidade como referentes para uma análise cuidadosa do crime organizado. As articulações entre as redes sociais diretamente implicadas nas atividades criminosas (as chamadas "redes submersas") com as redes que transitam pelo mundo "legal" envolvem gradações variadas. Por outro lado, no próprio universo social comumente identificado como solo fértil para o florescimento de grupos envolvidos com atividades delituosas, as redes sociais criminosas traduzem hierarquias e valores geralmente desconsiderados em muitas análises. O caso abaixo descrito aporta elementos para uma compreensão da complexa constituição das redes criminosas e de suas relações com o "mundo da superfície” (nesse caso, polícias estaduais). 
Figura 2

\section{As Redes Sociais do Crime Organizado e seus Contextos}

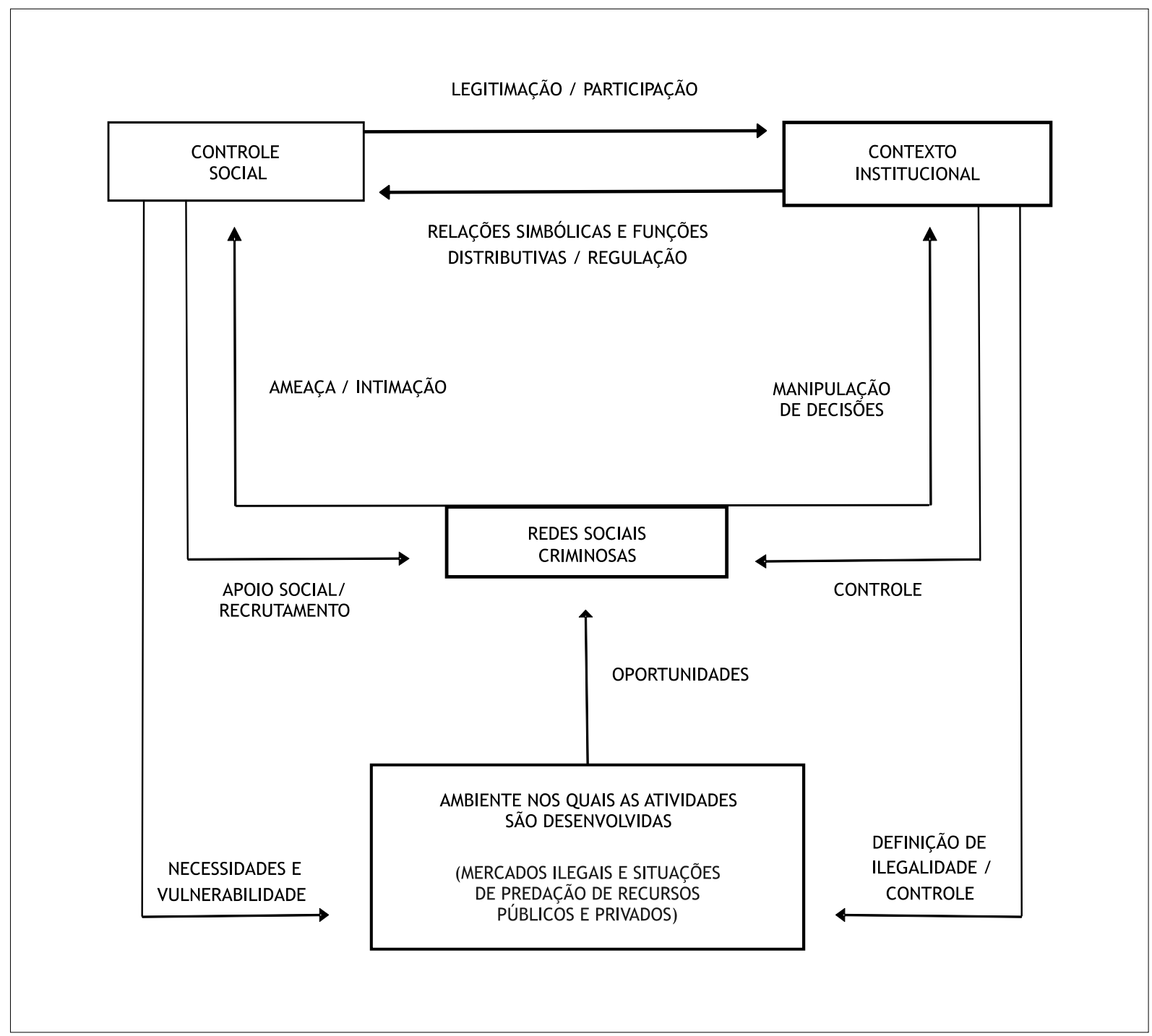

Fonte: von Lampe (2005).

Foi durante o curto período de sua prisão na sede da Polícia Federal no Ceará, localizada no Bairro de Fátima, em Fortaleza (CE), que o assaltante de bancos F. B. C., morto no final de 2005, conheceu J. D. P., um assaltante de pequenos estabelecimentos comerciais e agências de correios. J. D. P. lhe falou de José Roberto dos Santos Nogueira, que, então, já era acusado, pela polícia cearense, da prática de assaltos a bancos e de realizar assassinatos por encomenda em municípios da região do Vale do Jaguari- be, no leste do estado do Ceará, na divisa com o Rio Grande do Norte. A fama do jovem cearense já ultrapassara a Chapada do Apodi no oeste do RN e, como ficamos sabendo em uma entrevista realizada com um dos advogados de F.B.C., este já tinha "ouvido falar dele". Muito particularmente da sua participação na "Chacina de Limoeiro", crime no qual sete pessoas foram mortas e tiveram suas orelhas arrancadas, como forma de enviar um "recado" para as autoridades policiais que, no desenvolvimento de 
investigações a respeito do assassinato do radialista Nicanor Linhares (crime também atribuído a José Roberto), haviam prendido a esposa deste em Mossoró (RN). Algumas das pessoas assassinadas teriam fornecido informações que possibilitaram aquela prisão.

Quando, num dia de "nossa Senhora da Conceição" (8 de dezembro de 2003), como fez questão de enfatizar, conseguiu o feito inédito de fugir da cela onde se encontrava na sede da PF cearense (algo que, desde a sua inauguração, em 1974, ainda não havia ocorrido), F.B.C. já tinha mantido contato, por meio de terceiros que organizaram a sua fuga, com José Roberto, então já conhecido como "Chico Orelha". Segundo ele, sua fuga só teria sido possível porque contou com o apoio de "um pessoal muito bom lá do Jaguaribe". Entre risos, o advogado de F.B.C. nos contou (versão que um policial civil cearense, com quem conversamos, disse-nos não passar de fantasia e de exercício de auto-promoção do assaltante) que a operação toda havia custado cerca de $\mathrm{R} \$$ 500.000,00 (quinhentos mil reais). Uma das pessoas envolvidas na operação (exatamente a que dirigia o veículo que lhe tirou de Fortaleza) era de Tabuleiro do Norte (CE) e já havia atuado com José Roberto. Sabendo das dificuldades deste último, dado que a polícia estava no seu encalço, além de estar com alguns dos seus na prisão, FBC teve a idéia de convidá-lo para "umas empreitadas".

Após algum tempo de conversa, o advogado propôs-nos entrevistar o próprio FBC, via celular. Estávamos em Mossoró e, segundo, o advogado, ele tinha o número do telefone de F.B.C. daquela semana. Com base em anotações feitas após nossa conversa, o que F.B.C. disse sobre o episódio foi mais ou menos o que aponto abaixo:

Eu estava também desesperado. Quando você cai preso, não é ruim só porque você tá na prisão, mas é ruim, acima de tudo, porque a sua família paga um preço alto. Todo mundo quer tirar uma casquinha tanto policial quanto "vagabundo". E, o pior, os negócios vão tudo por água abaixo. Daí que a gente tem que fazer de tudo para tirar os cabeças, né? Porque a gente resolve... Mas aí tem que ter muito dinheiro. E dinheiro você sabe onde tem, né? [risos].

Citamos esse trecho porque ele é ilustrativo daquele traço, identificado por Machado (1995), como a emergência, no Brasil, de certa "sociabilidade vio- lenta". Um dos elementos constitutivos dessa "nova" sociabilidade seria a "instrumentabilidade do outro". Entendemos que esse é um elemento importante para pensar a respeito do baixo grau de solidariedade presente em algumas das novas organizações criminosas que emergiram nos últimos anos. Pensamos, em particular, nas quadrilhas especializadas no assalto a agências bancárias no interior do Nordeste.

Nesse sentido, vale a pena especular que o resgate de presos, um empreendimento de alto risco e de elevados custos financeiros (pelo aluguel de armas e contratação de pessoal), uma atividade quase rotineira para algumas das quadrilhas que se especializaram na prática do assalto a bancos no interior do Nordeste (penso naquelas identificadas pelos nomes familiares de alguns dos seus chefes), cada vez mais encontra a sua justificação em uma apreensão que poderíamos denominar "técnica", e não na mobilização de valores que diriam respeito à dimensão do afeto.

É essa instrumentabilidade que marca o relacionamento do grupo de F.B.C. com José Roberto. Por mais fantasiosa que possa ser a versão para a morte de José Roberto, elaborada por um jornalista cearense que entrevistamos (versão a qual, depois, apresentada a um advogado especialista na defesa de assaltantes, recebeu o veredicto de "mais do que factível"), ela pode ser tomada como referente para pensar essa instrumentabilidade. Segundo o jornalista, e não sem se gabar que contava tal fato alicerçado em fontes policiais, o que teria ocorrido foi uma negociação envolvendo as polícias do RN e do Ceará e o grupo de F.B.C. A prisão ou morte de José Roberto era uma “questão de honra" para a polícia cearense, dado o clamor causado tanto pela morte do jornalista Nicanor Linhares quanto pela chacina. Quando o setor de inteligência confirmou a ligação do pistoleiro com o grupo potiguar, foi fácil propor a entrega do pistoleiro.

Não questionamos F.B.C. sobre isso. Muito embora o seu advogado, em um arroubo, tenha afirmado que tínhamos "carta branca" para perguntar "qualquer coisa", confessamos, faltou-nos coragem (e, dado que tinha sempre que deixar claro, para mim mesmo, que não estava fazendo uma investigação policial, e sim uma investigação sociológica) para abordar tão delicado assunto. 
No que nos interessa mais de perto, a versão construída pelo jornalista a quem acabamos de nos referir indica-nos dois elementos importantes para pensar a estruturação das quadrilhas de assalto a bancos e, de resto, muitas das ditas "organizações criminosas" contemporâneas: a) a facilidade em mobilizar, nas ações criminosas, redes de relações que se constroem com base em encontros nas cadeias e presídios; e b) inseridas em um individualismo que se ancora, na relação com o outro, apenas na "cooperação técnica", essas redes apresentam baixo grau de solidariedade e confiabilidade.

Temos, então, no caso das redes sociais que alimentam as ações criminosas brasileiras, a reprodução de uma situação a qual poderíamos denominar de fragilidade estrutural: ligações extremamente necessárias, mas inseridas em um universo social no qual a instrumentabilidade do "outro" dinamita a durabilidade e o aprofundamento da confiança.

b) As redes de pilhagem do Estado

A permeabilidade do Estado aos interesses privados é uma das temáticas constitutivas das ciências sociais no Brasil. A inovação dos últimos anos tem se dado, como é o caso do pioneiro estudo de Marques (2000), pela introdução de novas metodologias na abordagem do fenômeno. $\mathrm{Na}$ antropologia, por exemplo, contamos já com um acúmulo de trabalhos que tomam a corrupção como objeto de pesquisa. Embora, de algum modo, se referencie na mesma gramática social - aquela que legitima a apropriação particular dos recursos públicos -, as atividades desveladas pelas operações realizadas pela Polícia Federal nos últimos anos apontam para uma alteração no formato de captura dos aparatos do Estado. Em lugar do clientelismo e da redistribuição assimétrica de recursos públicos, temos a predação sistemática desses recursos realizada em moldes empresariais.

Desde a prisão de um coronel da PM piauiense, no início desta década, acusado de comandar um esquema de rapinagem dos recursos de prefeituras de três estados (MA, PI e CE), por meio do fornecimento de notas frias, que a prática de pilhagem sistemática dos recursos públicos vem se sofisticando. Nesse caso, intimidação, chantagem e utilização da violência física eram recursos de convencimento para o envolvimento dos prefeitos. Deslocado de qualquer projeto político, a ação de pilhagem tinha no apoio de membros do corpo policial o seu sustentáculo. Esse caso, no entanto, expressa um estágio mais primitivo da pilhagem do Estado.

Para corroborar o que apontei acima, tomo como referência uma das principais operações desencadeadas pela Polícia Federal nos últimos anos. Refiro-me à "Operação Albatroz". As cifras e a forma de atuação do esquema identificado por essa operação, realizada principalmente no estado do Amazonas, em 2004, revelou o grau de sofisticação a que essa prática criminosa, que envolve, mas não se confunde com, a corrupção, chegou. Como em outros casos, revelados, por exemplo, pela CPI do Narcotráfico, a presença de parlamentares (deputados estaduais) não significa, como ocorrerá com práticas reveladas no decorrer do chamado "escândalo do mensalão", a subordinação da atividade a algum projeto político.

O envolvimento de magistrados - juízes e desembargadores, além de secretários de administrações estaduais - passa a ser uma característica dessas atividades de pilhagem. Os policiais locais participam agora, quando participam, de forma subordinada, fornecendo força de trabalho como seguranças ou força de reserva a ser empregada em situações excepcionais. Isso porque, como sói ocorrer em outros países, a corrupção cumpre geralmente o papel de substituir a violência física. Por outro lado, as atividades descobertas pela Polícia Federal revelam uma outra faceta: o aparecer social dos atores envolvidos com essas atividades é menos expresso pela ascensão e conquista de cargos políticos e, muito mais, pela adesão a um ethos de ostentação por intermédio do consumo de bens e serviços. Não por acaso, em todas as operações recentes temos a apreensão de automóveis de luxo. Essa cultura da ostentação - no consumo de bens e espaços - parece ser um traço em comum da economia subterrânea. Não por acaso as casas luxuosas e os carros of roads atraem tanto os barões mexicanos e colombianos da coca quanto os atores revelados pelas operações realizadas pela Polícia Federal.

Entretanto, as investigações apontam para um conjunto de práticas criminosas que, embora pareçam se alimentar da mesma gramática social que serve 
de referência para as práticas mais conhecidas - e, de algum modo, traços presentes na constituição do espaço público no Brasil -, como o aparelhamento do Estado, têm como diferencial a incorporação de métodos racionais de gerenciamento da pilhagem. $\mathrm{Na}$ medida em que, como no caso da "organização" desvelada pela Operação Albatroz, tais atividades implicam desenvolver atividades como a criação de empresas fictícias e o planejamento de formas para fraudar licitações de obras e serviços públicos, a presença de profissionais qualificados e com experiência de trabalho tanto no serviço público quanto em empresas privadas passa a ser algo cada vez mais usual.

Um dos espaços principais de atuação das redes de pilhagem do Estado se encontra no interior do sistema previdenciário brasileiro. As operações realizadas pela Polícia Federal apontam tanto para tradicionais atividades de fraudes (especialmente dedicadas a arrancar benefícios e aposentadorias indevidas) como para a criação de esquemas que permitam empresários burlar o pagamento devido de contribuições previdenciárias. Nesse caso, como naquele das fraudes em licitações de obras públicas, um traço que chama a atenção é a presença de advogados (característica tão importante a respeito do crime organizado na atualidade, que merece uma elaboração à parte e a qual já começa, em outros países, a impulsionar uma literatura especializada ${ }^{8}$ ).

\section{Conclusão}

A investigação sociológica sobre o crime organizado no Brasil ainda se encontra nos seus momentos iniciais. Não se trata, por certo, de temática das mais sedutoras. Os riscos, e não nos referimos apenas àqueles relacionados aos problemas de construção de nexos e deduções a partir de referentes empíricos recortados por algum arsenal metodológico, não podem ser desconsiderados. Entretanto, e essa é a nossa aposta, a sociologia pode, desde que não confunda a natureza da sua investigação (com a policial, por exemplo), fornecer importantes elementos para a reflexão dos atores políticos e sociais sobre um dos mais ameaçadores desafios à vida democrática na atualidade.
Não apenas motivações éticas e políticas justificam o desafio de tomar o crime organizado como objeto de análise. Questões teóricas de primeira grandeza podem ser desdobradas por meio dessa empreitada. Referimo-nos, dentre muitas outras, à tensão entre uma explanação da atividade delituosa ancorada na dimensão racional (o que pode levar a uma frutífera interrogação sobre a construção de escolhas racionais em cenários de radical incerteza) versus outra que realce o papel das regras e estruturas ou ainda que destaque a dimensão irracional nas ações. No que diz respeito à dimensão metodológica, como vem apontando Klaus von Lampe, a análise sociológica, ao focalizar as atividades, e não as organizações, pode impulsionar uma criativa incorporação da análise de redes no campo da criminologia.

Combinada a uma abordagem que incorpore alguns dos principais tópicos de discussão da NSE como, por exemplo, as noções de "mercados múltiplos", "habilidades sociais", vetores culturais da produção de instituições etc. - essa abordagem do crime organizado pode contribuir para superar lugares-comuns, reproduzidos pelo imaginário cinematográfico, os quais, muitas vezes, modulam as formulações dos responsáveis pela formulação das políticas de segurança. Gravitando no mesmo campo teórico, embora dotada de um estatuto próprio, a "história econômica institucional", desenvolvida por Avner Greif, fornece aportes que podem nos ajudar no desafio de apreender as transações que ocorrem em situação de radical incerteza. Especialmente ao demonstrar que, em tais contextos, os laços fracos, aliados à ausência de salvaguardas institucionais, contribuem para a reprodução de velhos modelos de patronagem.

Tal abordagem, acredito, pode ser extremamente fecunda para substanciar a análise das pontes e fronteiras entre as economias informal e ilícita. Nesse sentido, a ascensão do contrabando, da pirataria e de formas de usurpação das funções de regulação de diversos setores da vida econômica (especialmente àquelas relacionadas às ofertas e demandas das classes populares) expressa a importância estratégica desse tipo de investigação. Isso porque a perscrutação do contexto social e das instituições que emergem nessa ampla zona cinzenta de intersecção (entre o informal e o ilícito) pode nos fornecer importan- 
tes elementos para uma leitura menos pontual do capitalismo. E assim, de algum modo, aproximarmo-nos do ambicioso projeto desenhado por Richard Sweldberg (2003) para a NSE.

\section{Notas}

1 Para uma instigante análise sobre o discurso da pirataria como "epidemia", ver Yar (2005).

2 As profundas mudanças demográficas das últimas décadas, que redefiniram o lugar do urbano e do rural na sociedade brasileira, tiveram imensas conseqüências no que diz respeito à produção de reconhecimento social. Uma análise instigante, e que fornece importantes pistas para pensar essa situação, foi desenvolvida por Garcia Jr. (2003).

3 A análise de Caldeira (2000), com base em uma extensa e competente pesquisa etnográfica realizada na cidade de São Paulo, fornece importantes elementos para pensar o que, na linguagem da autora, denomina-se de "corpo incircunscrito" do brasileiro.

4 Ver, a respeito, Zelizer (1992).

5 De Mary Douglas. Refiro-me, em especial, ao excepcional livro Como as instituições pensam (Douglas, 1998).

6 Uma boa aplicação dessa abordagem teórica na literatura sociológica brasileira encontra-se em Monsma (2000). Ver a respeito Lopes Jr. (2007).

7 Uma referência, nessa questão, é o trabalho de Midd8 leton e Levi (2005).

\section{BIBLIOGRAFIA}

ALBANESE, Jay S. (2000), "The cause of organized crime: do criminal organize around opportunities for crime or do criminal opportunities create new offenders?". Journal of Contemporary Criminal Justice, 4 (18).

ALEXANDER, Jeffrey. (1987), "O novo movimento teórico”, Revista Brasileira de Ciências Sociais, 4 (2).

BAKER, Wayne E. \& FAULKNER, Robert. (1993), "The social organization of conspiracy: illegal networks in the heavy electrical equipment industry". American Sociological Review, 58.

BEARE, Margaret E. (1997), "Corruption and organized crime: lessons from history". Crime, Law and Social Change, 28.
CALDEIRA, Teresa Pires dos Rios. (2000), A cidade dos muros: crime, segregação urbana e cidadania em São Paulo. São Paulo, Editora 34.

CENTENO, Miguel Angel \& PORTES, Alejandro. "The informal economy in the shadow of the State". Disponível no site www.princeton.edu/ $\sim$ cenmiga/works. Acesso em: maio de 2006.

DAVIS, Mike. (2006), Planeta favela. São Paulo, Boitempo.

DE SOTO, Hernando. (1987), Economia subterrânea. uma análise da realidade peruana. Rio de Janeiro, Globo.

DOUGLAS, Mary. (1998), Como as instituições pensam. São Paulo, Editora da Unesp.

EMIRBAYER, Mustafá. (1997), "Manifesto for a relational sociology". The American Journal of Sociology, 2 (103).

FERNANDES, Florestan. (1978 [1965]), A integração do negro na sociedade de classes. São Paulo, Ática.

GARCIA Jr., Afrânio. (2003), "A sociologia rural no Brasil: entre escravos do passado e parceiros do futuro". Sociologias, 10.

GIDDENS, Anthony. (1993), As conseqüências da modernidade. São Paulo, Editora da Unesp. (1995), "A vida em uma sociedade pós-tradicional", in Anthony Giddens, Ulrich Beck e Scott Lash, A modernização reflexiva, São Paulo, Editora da Unesp. (2003), Modernidade e identidade. Rio de Janeiro, Jorge Zahar.

GRANOVETTER, Mark. (1985), "Economic action and social structure: the problem of embeddedness". American Journal of Sociology, 9. . (2005), "The social construction of corruption". Disponível no site http://www. economyandsociety.com (acessado em maio de 2005).

GREIF, Avner. (1993), “Contract enforceability and economic institutions in early trade: the Maghribi traders' coalition". American Economic Review, 3 (83). . (2004), "Teoria de juegos e historia de la empresa". Historia Empresarial, 812.

LOPES Jr., Edmilson. (2002), “Aportes para uma sociologia dos deslocamentos e das culturas móveis". Trabalho apresentado no XIII Encontro Nacional de Estudos de População. ABEP, Ouro Preto. 
. (2007), "Os cangaceiros viajam de

hilux: as novas faces do crime organizado no interior do nordeste do Brasil". Cronos, 1 e 2 (7). Disponível no site http://www.cchla. ufrn.br/cronos/v7n2/v7n1_artigos_3.pdf.

MACHADO, L. M. (1995), "Um problema na interpretação da criminalidade urbana violenta". Sociedade e Estado, 2.

MARQUES, E. C. (2000), Estado e redes sociais: permeabilidade e coesão nas políticas urbanas no Rio de Janeiro. Rio de Janeiro/São Paulo, Revan/Fapesp.

MIDDLETON, D. J. \& LEVI, M. (2005), "The role of solicitors in facilitating 'organized crime': situational crime opportunities and their regulation". Crime, Law \& Social Change, 42.

MONSMA, Karl. (2000), "Repensando a escolha racional e a teoria da agência: fazendeiros de gado e capatazes no século XIX”. Revista Brasileira de Ciências Sociais, 43 (15).

OLIVEIRA, Francisco de. (2003), Crítica da razão dualista: o ornitorrinco. São Paulo, Boitempo.

SOUSA, Jessé. (2003), A construção social da subcidadania: para uma sociologia política da modernidade periférica. Belo Horizonte, Editora da UFMG.

SWELDBERG, R. (2003), The sociology of capitalism: a introduction and agenda. Disponível no site www.economyandsociety.com/publications/wp5a_swedberg_03.pdf (acessado em maio de 2005).

VON LAMPE, K. (2003), “Criminal networks and trust". Trabalho apresentado no III Anual Meeting of the European Society of Criminology, Helsinque. Disponível no site http:/ / organizedcrime.de/criminalnetworkstrust.htm (acessado em maio de 2006). . (2005), "Making the second step before the first: assessing organized crime". Crime, Law and Social Change, 42.

YAR, Majid. (2005), “The global 'epidemic' of movie 'piracy': crime-wave of social construction?”. Media, Culture and Society, 5 (27).

ZELIZER, Viviana. (1979), Morals and markets: the development of life insurance in the United States. Nova York, Columbia University Press. . (1992), "Repenser le marche". Actes de la recherches em sciences sociales, 94. 


\section{AS REDES SOCIAIS DO CRIME ORGANIZADO: A PERSPECTIVA DA NOVA SOCIOLOGIA ECONÔMICA}

\section{Edmilson Lopes Júnior}

Palavras-Chave: Crime organizado; Redes sociais; Economia informal; Economia ilegal; Confiança e incerteza.

Este artigo aborda as redes sociais relacionadas com o crime organizado no Brasil. A análise apóia-se nos aportes teóricos e metodológicos de dois dos mais importantes movimentos teóricos da sociologia contemporânea: a análise de redes e a nova sociologia econômica. A empreitada analítica guia-se pela hipótese de que a melhor apreensão do crime organizado é aquela que o tome como um processo situado em um continum que vai da atividade legal até o evento delituoso. Assenta-se sobre a base empírica da narrativa sociológica, fornecida pelos relatórios de operações desenvolvidas pela Polícia Federal nos últimos três anos e por uma pesquisa já concluída sobre as quadrilhas especializadas no roubo a bancos no interior do Nordeste.

\section{SOCIAL NETWORKS OF THE ORGANIZED CRIME: A PERSPECTIVE OF THE NEW ECONOMIC SOCIOLOGY}

\section{Edmilson Lopes Júnior}

Keywords: Organized crime, Social networks, Informal economy, Illegal economy, Trust and uncertainty.

This article deals with social networks, directly or indirectly, linked to the organized crime in Brazil today. The analysis is based on the theoretical and methodological contributions of two of the most important theories in contemporary sociology: the analysis of networks and the new economic sociology. This analytic task is guided by the hypothesis that the best way to understand organized crime is one that takes it as a process situated on a continuum that goes from lawful activity to the criminal act. The empiric basis on which this sociological narrative is founded is supplied by the written reports of operations carried out by the Federal Police in the last three years and by a research already concluded on gangs specialized in robbing banks in the countryside of the Brazilian Northeast.
LES RÉSEAUX SOCIAUX DANS LE CRIME ORGANISÉ: LA PERSPECTIVE DE LA NOUVELLE SOCIOLOGIE ÉCONOMIQUE

\section{Edmilson Lopes Júnior}

Mots-clés: Crime organisé; Réseaux sociaux; Économie informelle; Économie illégale; Confiance et incertitude.

L'article propose une approche des réseaux sociaux liés au crime organisé au Brésil. L'analyse s'appuie sur les apports théoriques et méthodologiques de deux des plus importants mouvements théoriques de la sociologie contemporaine: l'analyse des réseaux et la nouvelle sociologie économique. Cette tâche analytique est guidée par l'hypothèse selon laquelle la meilleure compréhension du crime organisé est celle qui le considère en tant que processus situé dans un continum qui s'étend de l'activité légale à l'évènement délictueux. Ce travail s'appuie sur la base empirique de la narrative sociologique, fournie par les rapports des enquêtes effectuées par la Police Fédérale au cours des trois dernières années, ainsi que sur les résultats d'une recherche que nous avons développé sur les groupes de braquage de banques à l'intérieur du Nordeste brésilien. 